\title{
CAPITAL E INTERIOR: \\ MANIFESTAÇÕES EM PROL DA INSTRUCְÃO PÚBLICA EM OURO PRETO E UBERABINHA (MG) NOS ANOS INICIAIS DA REPÚBLICA BRASILEIRA
}

\author{
Wenceslau Gonçalves Neto*
}

RESUMO: Parte-se do princípio de que as cidades mineiras promoveram debates sobre a instrução popular, principalmente a partir de março de 1892, quando foram reabertas as Câmaras Municipais. As fontes utilizadas são Livros de Atas das Câmaras, livros de leis e documentação variada envolvendo os trabalhos dos vereadores. Em Uberabinha, onde havia carência gritante de escolas públicas, a edilidade assume essa preocupação como central, votando, ainda no ano de 1892, as leis de instrução pública, do regulamento escolar, das aulas noturnas e das circunscrições literárias, além de criar diversas escolas municipais. Em Ouro Preto, como a cidade era servida de escolas estaduais, as atenções da Câmara não se detêm firmemente na instrução elementar. Percebemos que a preocupação com a instrução pública estava difundida entre os municípios mineiros, embora não de forma homogênea.

Palavras-chave: Instrução Pública; Município e Educação; República e Educação.

CAPITAL AND HINTERLAND:

\section{MANIFESTATIONS IN FAVOR OF THE PUBLIC EDUCATION IN OURO PRETO} AND UBERABINHA (MG) IN THE STARTING YEARS OF THE BRAZILIAN REPUBLIC

ABSTRACT: It is taken for granted that the towns of Minas Gerais carried out debates about popular education, mainly starting from March, 1892, when the town-halls were reopen. The sources used were the town council protocol books, law books and varied documents of the works of the representatives. In Uberabinha, wherein there was a clear lack of public schools, the council of representatives considered this function a major duty, whereupon laws of public education, school regulations, evening classes and literary circumscriptions were voted in 1892, while schools in the town were founded. In Ouro Preto, where there already were public schools, the attention of the town council was not on primary education. It must be observed that public education as a main concern did not present a homogeneous form in every town of Minas Gerais.

Keywords: Public Education; Education and Town Circumscription; Republic and Education.

\footnotetext{
* Doutor em História pela Universidade de São Paulo (USP) e Professor do Instituto de História e dos Programas de PósGraduação em Educação e em História da Universidade Federal de Uberlândia (UFU). E-mail: wenceslau@ufu.br
} 
No mês de março de 1892, foram reabertas as Câmaras Municipais no estado de Minas Gerais, após dois anos de interrupção ocasionada pela proclamação da República e a consequente reorganização político-administrativa daí advinda. Geridas nesse ínterim pelos Conselhos de Intendência, nomeados diretamente pelo governo do estado, as cidades se prepararam para as novas regras que seriam delimitadas nas esferas federal e estadual. Para isso, o ano de 1891 foi decisivo, uma vez que, no seu decorrer, foram aprovadas a Constituição brasileira, em 24 de fevereiro (VIANNA, 1911), a Constituição do estado de Minas Gerais, em 15 de junho (VIANNA, 1911), e a lei mineira de número 2, de 14 de setembro de 1891, que "Contém a organização municipal” (MINAS GERAIS, 1892). Estava definido o aparato legal que permitiria o retorno à normalidade política no interior das cidades mineiras.

Essa lei orgânica dos municípios, nas disposições transitórias, estabeleceu, no artigo 91, que as eleições de vereadores, membros dos conselhos distritais e do agente executivo ocorreriam "no ultimo dia do mez de dezembro do corrente anno, e a primeira reunião das camaras e conselhos se fará no dia $1^{\circ}$ de março do anno de 1892". Também estabeleceu, no parágrafo segundo desse mesmo artigo, que o "mandato dos primeiros vereadores, dos primeiros agentes executivos municipaes e dos primeiros membros dos conselhos districtaes terminará no dia primeiro de janeiro de 1895".

Nosso período de análise prioriza, portanto, a primeira legislatura municipal mineira pós-república (1892-1894), acompanhando as discussões sobre educação que aconteceram no seu interior, deixando para análises futuras os desdobramentos dos anos seguintes. No entanto, para que não se perca a noção de conjunto e para mais esclarecimentos, incorporamos algumas referências dos tempos da Intendência, bem como discussões que antecedem ou sucedem o recorte delimitado.

Procurando evitar descrição e interpretação singulares, resolvemos acompanhar o debate nas câmaras de dois municípios do estado, buscando, no entanto, utilizar duas realidades muito distintas, para que possamos ter uma ideia mais clara das discrepâncias tanto de preocupações quanto de recursos disponíveis, materiais e humanos, para a implementação da instrução pública. Para isso, buscamos indícios nas atas das câmaras de Ouro Preto, então a capital do estado, e de Uberabinha (Uberlândia, a partir de 1929), um município interiorano. 
Além dessa diferença fundamental, as duas cidades apresentam várias outras que enriquecem o trabalho comparativo: Ouro Preto teve sua autonomia estabelecida em 1711 e Uberabinha, em 1888; Ouro Preto contou com experiência da Câmara Municipal desde o século XVIII e Uberabinha, apenas a partir de 1892; Ouro Preto dispunha de uma rede de instrução pública, incluindo duas escolas superiores, proporcionada por sua condição de capital, enquanto em Uberabinha havia oferta precária de instrução; Ouro Preto fora e continuava sendo um centro cultural no estado e Uberabinha se caracterizava por ser um burgo voltado para as atividades comerciais, sem qualquer lustro cultural; em Ouro Preto, o Conselho de Intendentes administrou uma estrutura consolidada e promoveu eleições para o retorno à normalidade política; em Uberabinha, esse conselho foi a primeira administração política efetiva da cidade, tendo não só de se ocupar das eleições, mas também da criação das condições materiais para o funcionamento do novo município; etc.

A primeira motivação para este trabalho foi buscar compreender como, na prática, se concretizaria a propaganda do Partido Republicano, que tecera pesadas críticas ao estado da instrução no período imperial e considerava a educação como a instância capaz de regenerar a população e estabelecer as bases para a consolidação da nova ordem que se iniciava. No Manifesto Republicano Federal de 1887, argumentava-se que a administração imperial teria resultado

no abandono da instrução pública, para que o povo continue imerso nas trevas da ignorância, com prejuízo da independência pessoal dos cidadãos e da fôrça fecundante do trabalho que tão útil devera ser ao Estado, mas que só é poderoso, eficiente e criador quando animado pelo influxo da inteligência esclarecida; no monopólio criado pela constituição de classes dirigentes, privilegiadas na sua própria instrução, à custa do imposto geral, e à quais estão efetivamente penhorada todas as posições oficiais (PESSOA, 1973, p. 86).

Essa crítica remete ao compromisso dos republicanos com a causa da instrução, o que pode ser claramente percebido, por exemplo, no Manifesto Republicano de Pernambuco, em 1888, onde se lê: "O que dissemos a este respeito applica-se ao ensino, funcção evidentemente espiritual. Neste particular o que a Republica deve ao povo - na epocha provisoria em que a familia proletaria não póde por si mesma preencher essa missão - é a instrucção primaria" (PESSOA, 1973, p. 109). 
Com a educação, seria possível, portanto, formar o novo cidadão, difundir os recém-criados símbolos da pátria, como bandeira, hino, heróis, brasão, etc., bem como ampliar o grau de conscientização e participação política desse cidadão republicano. A educação cumpriria, por esse caminho, abrangente papel civilizador e poderia ser considerada como uma proposta emblemática do partido republicano.

O segundo objetivo refere-se ao universo investigativo. Diversos estudos têm sido feitos tomando como referência as reformas promovidas na educação pelos governos estaduais, como a que foi feita por Afonso Pena, em Minas Gerais, por meio da lei n. 41, de 3 de agosto de 1892, que "Dá nova organização á instrucção publica do Estado de Minas” (MINAS GERAIS, 1893). No nosso caso, pretendemos verticalizar um pouco mais a investigação, focando nossa atenção sobre os municípios, para compreender tanto o grau de responsabilidade que a eles é atribuído quanto as iniciativas em prol da instrução pública identificadas nas ações e nos discursos proferidos nas câmaras municipais.

\section{A República em Minas Gerais}

Muito se tem debatido no Brasil sobre o grau de participação ou alheamento da população no movimento que proclamou a República (CARVALHO, 1998; MELLO, 2007). Não é nosso propósito retomar esse debate, apenas referenciar sua presença em Minas Gerais, visando a compreender melhor o peso dos militantes dessa forma de governo na antiga província. Segundo Oiliam José (1960, p. 28), até “1871, a situação política e militar da Província permaneceu, deste modo, infensa à expansão dos ideais republicanos". Apenas após o lançamento do Partido Republicano, em 1870, é que esses princípios começam a se difundir pelo espaço mineiro, impulsionados principalmente pelas ideias que se irradiavam a partir de Ouro Preto, de onde

terminando ali seus estudos de farmácia ou de engenharia ou, simplesmente, os secundários, os jovens partiam para o interior dispostos a fundar em suas localidades núcleos ou clubes republicanos e, com êles, agitar o povo contra a Monarquia. Também da Côrte e de São Paulo chegavam, ao interior da Província, mineiros formados em medicina, direito, farmácia ou engenharia e que, ao lado das doutrinas científicas especializadas em que se formaram, traziam as idéias republicanas vigentes nas duas famosas capitais (JOSÉ, 1960, p. 69). 
Pelo que está dito, percebemos que o esforço republicano mineiro era ainda incipiente, mas se alastrava pelo interior, particularmente entre a elite intelectualizada, que obtinha estudos fora de seus núcleos urbanos originais e para aí voltava para ocupar cargos ou profissões prestigiosos. Dados o pouco tempo para a fixação da ideia republicana e a distância dos principais centros difusores da propaganda, o que atingia principalmente o interior mineiro e as relações políticas locais compromissadas com os dois principais partidos do período imperial, liberal e conservador, o republicanismo em Minas não pode ser considerado como uma força significativa nos anos anteriores à proclamação de 15 de novembro de 1889. Apesar da presença de importantes líderes históricos republicanos na província, foram os mesmos alijados das discussões que culminaram na República, como nos atesta Maria Efigênia Lage de Resende (1982, p. 55), ao anotar que "Se a Proclamação da República foi uma surpresa para a população brasileira em geral, em Minas ela o foi também para os republicanos".

Oiliam José considera que essa fraqueza do Partido Republicano está ligada à falta de dinamismo na difusão dos ideais que embasavam o projeto de mudança de governo. Além disso, relembra a pouca profundidade das discussões, dificultando o aprimoramento do debate e, consequentemente, das propostas de ação. Segundo esse autor, "Dessa pobreza de doutrinação decorria, em Minas e em grande parte, o fato de a República não ter, mesmo em 1889, alcançado ainda fundas raízes no meio da gente mineira, como aliás não havia obtido no Brasil considerado em seu todo" (JOSÉ, 1960, p. 161). Como resultado desse alheamento das lideranças mineiras com as da Corte, observa-se que

entre julho e princípios de novembro de 1889, transcorria normalmente a vida em Minas, sem que algo de grave ou inesperado chamasse a atenção das autoridades e dos governadores. Nem os republicanos mais ardorosos sabiam o que, a respeito da República, ocorria no Rio de Janeiro. Mesmo nos dias que antecederam imediatamente o 15 de novembro algo de novo chegou ao conhecimento deles. '... Ignoravamos, em Ouro Preto tudo que se tramava no Rio para a proxima proclamação da Republica', di-lo-ia mais tarde Antonio Olyntho dos Santos Pires, um dos membros da Comissão Diretora do Partido Republicano em Minas” (JOSÉ, 1960, p. 140).

Desconsiderado na organização e na implementação do golpe militar que pôs fim à monarquia, o Partido Republicano Mineiro não teve 
apenas aí sua desdita. No processo de reorganização política, os líderes republicanos históricos acabaram preteridos pelo Governo Provisório, que escolheu Cesário Alvim para governar o novo estado, um recém-chegado às hostes partidárias, militante que fora de longa data nos quadros do Partido Liberal. Esse fato trará turbulências nas relações políticas no interior do estado que não são o foco do presente estudo.

Há que se ressaltar, ainda, com relação aos desdobramentos ocasionados com a implantação da República, a valorização por que passará a esfera municipal, pouco destacada durante o Império. A Constituição Federal de 1891, apesar de não se estender sobre a questão local, assegura, em seu artigo 68, a autonomia municipal, que deveria ser regulamentada pela legislação estadual. Os constituintes mineiros levaram avante o projeto de descentralização política e fixaram na Constituição estadual, por meio de sete artigos, princípios que reforçavam a autonomia acentuada do poder municipal, que alcançava, inclusive, os distritos, que passaram a ser considerados, pelo artigo primeiro da Lei n. 2 de 1891, que estabelecia as normas de funcionamento dos municípios, como "a base de organização administrativa do Estado de Minas Geraes" e o município, como uma reunião de distritos.

Esse liberalismo relacionado à descentralização do poder emerge com força no Congresso Constituinte mineiro, no qual os principais temas que ocuparam a atenção de deputados e senadores foram senado estadual, organização municipal e mudança da capital (SILVEIRA NETO, 1978). Logo em seguida à promulgação da Constituição estadual, foi aprovada a lei n. 2, já citada, que reservava às Câmaras Municipais ampla liberdade de ação, não podendo o governo estadual, pelo artigo 76, "intervir em negócios peculiares ao município, sinão no caso de perturbação da ordem publica”. Entre outros poderes garantidos aos municípios, o parágrafo segundo do artigo 37 determinava que as câmaras poderiam deliberar

Sobre a instrucção primaria e profissional: creando escolas, provendo-as com professores idoneos, para o que instituirá o concurso, como principal meio de prova de capacidade intellectual, processado perante commissões de sua confiança e nomeação; inspeccionando e fiscalizando o ensino, fazendo com que nelle sejam empregados os methodos mais aperfeiçoados e modernos; marcando os vencimentos dos professores; creando e suprimindo officinas para o aprendizado das artes liberaes e fundando outros estabelecimentos de instrucção profissional; estabelecendo o fundo escolar e consignando verbas em seus orçamentos para os serviços que crear; regulando-as, emfim, como 
entender conveniente, devendo os professores municipaes apresentar mensalmente aos encarregados da fiscalisação do ensino, por parte do Estado, mappas de frequencia das respectivas escolas.

Do que está colocado, percebemos que o republicanismo mineiro, apesar de ainda não arraigado, encontrava-se em expansão, formando um núcleo aguerrido em torno de algumas lideranças históricas, mas que não participou diretamente da montagem e da execução do movimento que culminou na República. Por outro lado, podemos observar que o Congresso Constituinte mineiro assumiu as propostas federativas e descentralizadoras, remetendo aos municípios um amplo conjunto de direitos, os quais incluíam a organização da instrução pública em seus territórios. E isso nos permite retornar à discussão sobre a educação no interior das câmaras, como entidades suficientemente legitimadas para promover esse debate.

Por último, é importante lembrar que essa autonomia municipal não terá vida longa. $\mathrm{Na}$ tentativa de consolidar o poder oligárquico, o governo estadual irá gradativamente retirando as prerrogativas municipais, processo que pode ser considerado completo por volta de 1903 (GONÇALVES NETO, 2007).

\section{A inauguração das novas Câmaras Municipais}

Março de 1892 trazia grandes esperanças para todo o estado de Minas Gerais, com a volta à normalidade política no nível municipal concretizada pela reabertura das câmaras. No caso das cidades em evidência, Uberabinha e Ouro Preto, como já dissemos, as diferenças eram bem marcadas. Acrescente-se que, enquanto Ouro Preto contava com uma experiência secular de exercício da Câmara e tivera a Intendência Municipal funcionando por dois anos, no prosseguimento dos trabalhos legislativos e administrativos, Uberabinha não tinha qualquer passado de vida política local e sua Intendência atuara apenas por um ano, preparando as condições para a implantação da primeira Câmara Municipal.

Mesmo assim, o dia 7 de março foi festivo nas duas localidades, guardadas as proporções de pompa. Em Uberabinha, a formalidade circunscreveu-se à reunião do Conselho da Intendência para transposição dos cargos de comando, mas, ainda assim, com cerimonial à altura da ocasião, presidido pela administração que findava: 
...achando-se na salla contigua diversos membros da Câmara Municipal, dos Conselhos districtaes e Juizes de Paz eleitos e tendo de ser introduzidos no recintho das sessões para tomarem posse desiguinava dois membros do Conselho Municipal para os receberem e acompanharem até a meza. Sendo recebida a incumbencia pelos os ditos membros do Conselho dirigirão a salla indicada e recebidos os cidadãos ali prezentes voltarão a salla das sessões acompanhados dos seguintes cidadãos....

Esse singelo protocolo de Uberabinha é sobejamente superado pelas solenidades ouro-pretanas. Lá, "voltando de assistir na Igreja Matriz de Ouro Preto á missa votiva do Espirito Santo", reuniram-se os vereadores para a instalação da Câmara. O presidente da casa nomeou uma comissão para dar entrada ao recinto ao presidente do estado de Minas Gerais, Ernesto da Gama Cerqueira, que ocupou lugar na mesa ao lado dos presidentes da Câmara e da Intendência, seguindo as "formalidades do estylo". Tem início, então, longa cerimônia, da qual se salientam os discursos das autoridades:

Sobre o livro dos Santos Evangelhos prestão então juramento, cada um a seu turno, o snr. presidente e agente executivo e os snrs. vereadores acima mencionados. Findo este acto solemne, celebrado em presença de numeroso concurso de todas as classes sociaes da cidade, levanta-se o exmo. snr. presidente do Estado para exprimir o intimo jubilo que sente, assistindo á posse da Camara da Capital. Congratula-se com todo o Estado pelo criterio, prudencia, moderação e regularidade com que se fizerão as recentes eleições districtaes e municipaes, por ventura as mais livres e espontaneas de quantas até então se havião feito. Tendo já externado os mesmos sentimentos no acto de clemencia com que entendeo perpetuar a memoria deste dia e que dentro em pouco será lido, manisfesta os seus sinceros votos pela crescente prosperidade desta illustre Capital, cujos importantes melhoramentos, indicados no relatorio da administração transacta, certamente reclamão o mais vivo interesse da nova Camara; concluindo por erguer um brado de saudação á integridade do territorio mineiro, brado que enthusiastica e unanimamente é echoado por todos os assistentes. Á s. exa . corresponde o snr. presidente da Camara, fasendo a leitura do decreto de hoje, pelo qual receberão indulto vinte e tres sentenciados em varios pontos do Estado. Acompanhando depois as honrosas manifestações do nobre presidente de Minas, á s. ex ${ }^{a}$., em nome da Camara e de todos os municipes da Capital do Estado, agradece a gentilesa de sua presença a este acto e longamente se detem na fiel rememoração do que tem sido o distincto civismo deste altivo e brioso povo ouro-pretano em todos os tempos, como no actual, em que s. ex ${ }^{\mathrm{a}}$, como legitimo representante do poder publico, nelle encontra, segura e inquebrantavel, a mais constante e patriotica 
dedicação. Secundando mais uma vez o brinde erguido á integridade inviolavel do grande Estado Mineiro, convida os assistentes a acompanha-lo na saudação que dirige ao digno presidente de Minas Geraes, terminando por apresentar-lhe, em nome daqueles que s. exa . neste dia restituio á liberdade e á patria, um quadro allusivo a tão generoso rasgo de clemencia. No meio de ruidosas acclamações, retira-se o exmo. snr. presidente do Estado com as mesmas formalidades com que fôra recebido ${ }^{2}$.

A pompa e a grandiosidade da cerimônia são garantidas tanto pelo cerimonial refinado quanto pela presença do presidente do estado. Além disso, os discursos proferidos revelam a aproximação entre os governos da Câmara e do estado e, é claro, uma ligação também com os recursos do tesouro estadual. Para completar as comemorações, novamente se volta a Câmara para as atividades religiosas que as começaram, convidando o presidente aos vereadores para dirigirem-se, às 17h, à capela de São Francisco de Assis, onde assistiriam "á celebração do solemne Te-Deum laudamos, que será entoado em acção de graças do Todo Poderoso e depois no paço illuminado da Camara para recepção das pessoas que concorrerem".

Usamos esses exemplos para demonstrar que as câmaras retornavam à atividade com legitimidade assegurada pela lei e pelo voto que garantira a eleição dos vereadores. Mas essa Câmara republicana mineira em muito se diferencia de sua antecessora do período imperial, já que, como vimos, tanto a Constituição estadual quanto a lei orgânica dos municípios asseguravam-lhe ampla autonomia político-administrativa. Com essa descentralização de decisões e liberdade para ação poder-se-ia esperar intervenções substantivas por parte do poder municipal nos principais problemas que afligiam a localidade. Entre essas iniciativas a educação, por ter sido tratada no programa republicano com destaque, deveria receber cuidado especial, buscando-se superar a atmosfera de barbárie que teria sido herdada do Império.

Vejamos, portanto, como as câmaras de Ouro Preto e Uberabinha, em suas sessões, procuraram ocupar-se com as questões da educação em geral e da instrução pública em particular. 


\section{A Câmara Municipal de Ouro Preto e a educação}

Como indicamos antes, as câmaras poderiam operar livremente no campo da instrução pública, criando escolas, contratando professores, fiscalizando as atividades, etc. Em Ouro Preto, no entanto, pouco será feito nessa direção. E a explicação é objetiva: como capital, privilegiadamente em relação às outras cidades, já contava com uma rede de escolas estaduais de primeiras letras que dispensava a Câmara dessa responsabilidade, o que pode ser encontrado em diversas passagens das atas. Em 4 de maio de 1892, num parecer sobre a escolha de livros para serem utilizados nas escolas, a comissão responsável abriu sua ponderação da seguinte forma: "Considerando que a Câmara não possue ainda escolas suas, sendo do Estado todas as que existem no município". Em 18 de agosto do mesmo ano foi aprovada uma proposta nos seguintes termos: "Indicamos que a Camara da Capital consinta que os exames feitos no collegio da Cachoeira do Campo, fundado pelo Revmo. Sr. Padre Theodolino José Fagundes para instrucção primaria e secundaria do sexo masculino, sejão validos para os candidatos ao magisterio das escolas municipaes, que opportunamente serão fundadas".

Sem pressão ou demanda pela criação de escolas, a Câmara pouco debateu sobre educação no primeiro ano de funcionamento. Nem mesmo uma lei de instrução pública foi submetida à apreciação da edilidade, aparecendo menções à mesma apenas no ano de 1894, mas para informar sobre a sua inexistência, como podemos ver por um parecer de 27 de outubro desse ano: "que em quanto não houver legislação reguladora do ensino primário municipal e rubrica orçamentaria especialmente destinada a esse ramo de serviço, inoportuna será a criação de cadeiras como...". Observação no mesmo sentido será encontrada na ata do dia 10 de novembro.

No entanto, há que se analisar com cuidado esse aparente descaso com a instrução. Antes de mais nada, é preciso destacar que existiam escolas, embora fossem de responsabilidade do estado. Em segundo lugar, é importante observar que existem algumas contradições nos registros da Câmara, embora ainda não tenhamos elementos para dirimir a dúvida. Por exemplo, em 1891, primeiro ano de responsabilidade da Intendência, encontramos uma referência no dia 13 de junho sobre a aprovação de criação de escolas: "Pelo Intendente Doutor Penido, foi apresentada uma indicação no sentido de que sejão creadas quatro escolas nocturnas nos 
bairros das Cabeças, Ouro Preto, Antonio Dias e Alto da Cruz, determinando-se que nos contractos com a Intendência, se fixe uma quota para o estabelecimento e custeio das referidas escolas".

Apesar de serem escolas noturnas, o registro remete à existência de escolas municipais, além de expor a presença de demanda não atendida por instrução na capital do estado pelo menos para a população adulta, o que pode ser presumido inclusive pelo fato de serem criadas quatro escolas de uma só vez. Além disso, outros indícios remetem à ação municipal envolvendo a educação, como em 3 de setembro do mesmo ano, quando o mesmo Intendente fez aprovar uma indicação no sentido de que "seja creada uma secção de instrucção publica, composta de um dos officiaes da Secretaria e dous amanuenses, nomeando-se estes e determinando-se os respectivos vencimentos...”.

Por essas passagens percebemos que a educação podia não ser o foco dos debates da Intendência de Ouro Preto, mas fazia parte de suas preocupações. E essa atenção persiste na Câmara legalmente constituída a partir de 1892, embora a discussão seja marginal nesse primeiro ano, não resultando efetivamente na criação de escolas ou na definição de uma legislação específica, o que pode ser visto pela descrição dos momentos mais relevantes em que a Câmara se ocupou do assunto.

Em 20 de abril de 1892, o vereador Pe. Camillo Velloso "vem hoje occupar-se das escolas em que a infancia se deve preparar, habilitarse para em breve vir a ser digna herdeira do futuro da pátria", chamando a atenção para os perigos do ensino depois que foi definido seu caráter leigo pelo Governo Provisório da República e referendado pela Constituição Federal de 1891. Buscando "neutralisar os pessimos effeitos da satanica suppressão do cathechismo nas escolas", propôs que a Câmara adquira 2 mil exemplares dos poemas sacros, intitulados Heroínas do Evangelho. A moção é recusada, pois somente o estado poderia decidir sobre essa questão, uma vez que as escolas eram de sua responsabilidade.

$\mathrm{Na}$ sessão de 14 de maio, foi aprovada uma proposição que demonstra preocupação do poder municipal com a instrução da população e, ao mesmo tempo, nos permite compreender um pouco a situação aflitiva em que viviam os professores públicos naqueles tempos:

Considerando que os professores de primeiras lettras no nosso Estado formão uma das classes menos favorecidas, já em regra geral e já nos minguados ordenados que percebem; Considerando que além das grandes difficuldades 
com que lutão pela carestia dos géneros, têm se creado impostos sem excepção de classes; Considerando que alguns d'elles, além de cumprirem com seus deveres, ainda concorrem com o predio de sua propriedade para nelle funcionar a aula publica, sem que por isso recebão alugueis; A Camara resolve que fiquem isentos do direito predial todo o predio que for de propriedade do professor e que n'elle funccionem as aulas publicas sem remuneração de aluguel.

É preciso lembrar também que existiu um projeto de apoio à criação de uma escola ainda nesse ano de 1892, mas para o ensino secundário, e não para o ensino elementar. Em 8 de julho, é apresentada a proposta para auxílio na criação do colégio, constando a sua aprovação, mas os registros sobre o mesmo nas atas da Câmara não reaparecem. Justificase o projeto por "uma falta, que muito nos importa attender, por não ser vantajosa aos créditos da cidade. Refiro-me a um collegio de instrucção secundaria para as meninas". Embora seja louvável a iniciativa, a primeira justificativa apresentada foi a forma como Ouro Preto seria vista pelas outras cidades, e não uma preocupação genuinamente voltada para as meninas e para a educação de forma particular. No projeto consta:

Art. $1^{\circ}$. Fica o agente executivo autorisado a promover a organisação de um collegio destinado á educação de meninas; podendo auxiliar a sua fundação com valores, cujos juros não excedam a um conto de reis annuaes. Art. $2^{\circ}$. O collegio se obrigará a dotar com dusentos mil reis á tres orphans do asylo municipal, começando esta obrigação no fim do seu segundo anno de existencia; e, quando o asylo ainda não tenha orphan em idade nubil, os tres dotes serão dados á moças de familia pobre deste municipio, a juiso da Sociedade de Santa Izabel. Art. $3^{\circ}$. No caso de liquidação do collegio, os valores reverterão ao patrimonio municipal. Art. $4^{\circ}$. Revogão-se as disposições em contrario.

O debate propriamente dito sobre a instrução popular foi inaugurado apenas em 13 de dezembro de 1892, quando é apresentada proposta de criação de uma cadeira mista de instrução primária no lugar chamado São Gonçalo do Bação, a qual, no entanto, só entrará em discussão um ano depois, em 16 de dezembro de 1893. Essa proposta, contudo, não entusiasmou os vereadores, preocupados com a situação das finanças municipais, sendo na ata desse dia anotada a posição contrária: "em quanto as circumstancias da câmara não permittirem a organisação de um plano geral de criação de escolas a expensas do municipio, medidas parciaes, como a de que ora se trata, constituem precedentes que a obrigarão 
a generalisar o estabelecimento de cadeiras, sem que para tanto disponha ella dos necessarios recursos". Apesar dos apelos do vereador proponente, chamando a atenção para a injustiça que se cometia contra a população do Bação, privados que estavam os meninos de escola, porque "só se lhes offerece á longa distancia e com a interposição de rios", acaba por ser votado um substitutivo determinando: "A câmara creará cadeiras de instrucção em todos os districtos e lugares que se sujeitarem á taxa escolar na rasão de mil reis por habitante".

Os protestos contra esse encaminhamento abriram uma divisão na Câmara, mas foram insuficientes para alterar o substitutivo. Apesar de declarações considerando a taxa escolar "como imposição a mais vexatoria que aos districtos se possa fazer, como um verdadeiro presente de gregos, envolvendo um onus a que não esta sujeito nenhum outro districto dos de Minas", na sessão do dia 19 de dezembro de 1893, essa medida é aprovada. Mas com uma exceção: o Bação passou a contar com uma escola a expensas do município, recebendo consignação no orçamento do próximo ano no valor Rs $720 \$ 000$.

Apesar de não dispor ainda de uma legislação específica da instrução elementar, o município de Ouro Preto já sinalizara, no final de 1893, qual seria sua posição sobre essa questão. Remetia aos distritos a responsabilidade pela abertura de escolas, financiadas pela taxa escolar que se cobraria da população. Enquanto isso, Ouro Preto continuaria gozando do privilégio de ter suas escolas mantidas pelo tesouro estadual. Ou seja, a omissão do poder público que se notara com relação aos negócios da instrução durante o Império permanecia na nova forma de governo na capital do estado de Minas Gerais.

No caso de Ouro Preto, atendida por escolas estaduais de primeiras letras, a discussão sobre a responsabilidade pela instrução pública no nível municipal será deflagrada por uma motivação quase "externa", pelos distritos, para os quais a Câmara não se dispunha a fazer o devido investimento, não enfrentando o problema e remetendo aos próprios distritos a responsabilidade pelo financiamento da instrução a que aspiravam. Como os representantes do distrito-sede eram em maior número no interior da Câmara, o problema da criação ou da ampliação das escolas primárias nos distritos foi tangenciado. 


\section{A Câmara Municipal de Uberabinha e a educação}

As diferenças entre a atuação das duas câmaras não se resume ao cerimonial de posse já apresentado, avançando, entre outros aspectos, para o enfrentamento das questões educacionais. Diversamente do ocorrido em Ouro Preto, a edilidade uberabinhense coloca as questões da instrução como centrais desde a sessão inaugural, reconhecendo a existência de uma demanda reprimida nos limites do município. Ainda no dia 7 de março de 1892, logo após a solenidade de posse,

tomando a palavra o Snr. Arlindo Teixeira leu e mandou a meza uma proposta authorizando a Câmara a prover interinamente a aula primaria do sexo masculino desta cidade e ocorrer as despezas pela cobrança da Taxa escolar cobrada com a denominação imposto de capitação. Posta em discussão e não havendo quem pidisse a palavra posta a votos foi aprovada.

Vemos aí várias sinalizações para o problema que nos interessa: 1) em Uberabinha, a Câmara atrelou à sua inauguração a autorização para o provimento de escola municipal, retomando, por meio dessa ação, uma das bandeiras do programa republicano; 2) a instrução pública estava entre as principais preocupações da população, pouco assistida em seu período de subordinação distrital do vizinho município de Uberaba, sendo necessária uma resposta imediata; 3) definiu-se, já nesse momento, a cobrança de uma taxa escolar para financiamento dos gastos com a instrução, a qual é aprovada sem discussão, o que sinaliza a percepção do descaso do estado para com essa questão, assumindo os vereadores, de antemão, a responsabilidade pela criação e pela manutenção de escolas.

Na primeira sessão de trabalhos, em 8 de abril de 1892, duas outras providências concernentes à educação foram tomadas: autorizouse a Câmara a "mandar abrir uma parede divizoria da caza de instrucção publica desta cidade, por não comportar os devidos numeros de alumnos existentes e freqüentes", o que expõe a precariedade material da infraestrutura escolar municipal; em seguida, propõe-se que a Câmara dispense "a prova de capacidade intelectual do Professor municipal Eduardo José Bernardes para invistimento do titulo de Professor effectivo", o que expõe também a fragilidade local para conseguir professores suficientemente qualificados. 
Na sessão seguinte, em 9 de abril, aprovou-se oficialmente a criação da taxa escolar, conforme consta da ata: "Fica criado o imposto de taxa escolar a razão de 3:000 reis, por cada individuo maior de vinte e um annos, que constitua a economia domestica e independente. Exceptuãose os mendingos e interdictos". Chama a atenção, como já observamos, a rapidez com que se aprova a criação do novo imposto, inclusive com valor muito superior ao estabelecido em Ouro Preto, que era de mil réis. Contudo, devemos anotar que a cobrança dessa taxa não deve ter sido tranquila, uma vez que, em 28 de dezembro de 1893, na discussão do orçamento para o ano seguinte, um vereador apresenta proposta no seguinte sentido: "Suprima-se este paragrapho em vista da má vontade do povo para o pagamento do imposto escollar". Apesar de a ideia não ter sido aceita, ficam claras a insatisfação da população com relação ao imposto, bem como as dificuldades da Câmara para garantir a manutenção das escolas municipais.

Mas a maior evidência da centralidade da educação e da celeridade nos trabalhos da Câmara sobre o assunto encontra-se na proposta de criação de regulamentação escolar para o município apresentada no dia 12 de abril. Discutida ao longo dos próximos dias, o projeto foi aprovado em última votação no dia 22 de abril, resultando na lei n. 1 do município de Uberabinha, "Que dispõe sobre instrucção publica"3. Nesse mesmo dia, elege-se uma comissão para elaborar o regimento escolar da cidade, sendo seu projeto apresentado no dia 10 de junho. Após rápida discussão em duas sessões, foi aprovada, no dia 16 de junho, a lei n. 2 de Uberabinha, "Que dispõe sobre o regulamento escolar".

Dando sequência a esse afã legislativo, no mesmo dia 16 de junho, deu-se entrada a um projeto imediatamente aprovado como a lei n. 3 de Uberabinha, "Que dispõe sobre as aulas noturnas". E, no dia 17 de junho, foi aprovada a lei n. 4 do município, "Que dispõe sobre a divizão das zonas litterarias dos districtos da cidade de Uberabinha”, estabelecendo a distribuição espacial das escolas municipais.

Podemos notar como Uberabinha se apressa em gerar uma legislação que ampare suas ambições instrucionais, compondo, em dois meses, o aparato legal para o funcionamento do ensino, incluindo a criação de um imposto específico para sustentar o zelo educativo da Câmara. Devese chamar a atenção, inclusive, para a precocidade dessa iniciativa, pois a lei da instrução pública da cidade antecede em mais de três meses a lei n. 
41 do estado de Minas Gerais, que "Dá nova organização á instrucção publica do Estado de Minas", que é de 3 de agosto de 1892 (MINAS GERAIS, 1893). Com relação ao regulamento escolar, a precedência é ainda maior, já que o decreto mineiro n. 655, que "Promulga o regulamento das escolas e instrucção primaria", é de 17 de outubro de 1893 (MINAS GERAIS, 1894), 16 meses posterior ao de Uberabinha.

Outra diferença significativa entre Ouro Preto e Uberabinha está no número e no ritmo de criação de escolas, o que seria de se esperar, já que Uberabinha não contava com o privilégio ouro-pretano de ter um número significativo de cadeiras escolares de responsabilidade estadual em seus domínios. No entanto, existia uma, conforme se depreende de correspondência da Inspectoria de Instrucção lida na Câmara em 14 de julho de 1892, comunicando a nomeação de "professor estadual da escola da instrucção primaria desta cidade". No entanto, pelas iniciativas da Câmara, podemos presumir que essa aula estadual estava longe de atender a demanda educacional da cidade.

Por essas circunstâncias, além do provimento da cadeira do sexo masculino na cidade, decidida na sessão inaugural da Câmara, logo em 22 de abril foi proposta a criação de "uma aula nocturna do sexo masculino nesta cidade, regida pelo professor municipal cidadão Eduardo José Bernardes", o mesmo que havia sido recentemente nomeado para a aula diurna, após dispensa da prova de capacidade intelectual. Essa moção significa que a demanda por instrução em Uberabinha aparecia também entre o público adulto, justificando a abertura dessa nova escola, talvez antecipando o espírito da lei das aulas noturnas, que foi aprovada menos de dois meses depois. Em 6 de junho, esse professor municipal solicitou a nomeação de um auxiliar, para dar conta do número elevado de crianças sob sua responsabilidade, e foi atendido em seu pleito, duplicando a capacidade de atendimento dessa escola.

Também se depreende a existência de escolas rurais a cargo do município, pela anotação na ata de 17 de junho de uma emenda "elevando os ordenados dos professores ruraes a um conto e quatrocentos mil reis". E a demanda por essas escolas continuava presente: em 14 de julho é apresentado um requerimento, assinado por diversos cidadãos, pedindo a criação de uma escola municipal no bairro Rio das Pedras, que foi aprovado na sessão do dia 19 de julho. Nessa mesma data, identifica-se a contribuição privada no provimento da instrução municipal: "Foi prezente 
pelo Snr. Prezidente, uma declaração do cidadão Joaquim Alves de Carvalho, offerecendo meio alqueire de terreno na fazenda do Marchante no lugar denominado Pindahyba do Capão Secco, para edificação de uma caza para escola publica".

O ano de 1893 iniciou-se com a criação de duas escolas rurais e a concessão de subvenções a professores particulares, o que mostra que a oferta ainda não fora suficiente para atender aos reclamos e às necessidades do município que nascia. É importante anotar que o concurso da iniciativa particular estava previsto na lei de instrução estadual e referendado no regimento escolar do município, permitindo a terceirização de parte das responsabilidades escolares. Na sessão de 14 de janeiro, foi apresentado o seguinte parecer:

Esta commissão nutre a esperança de que, em face da organização do orçamento actual, sendo feita a arrecadação regularmente, o município poderá fazer face as diversas dispezas que são mister para seu progresso; por tanto afirma que: primeiro; sejão providas as escolas das zonas - Tenda e Sobradinho, autorizando ao agente executivo a pôl-as em concurso para seu provimento e assim também, a conceder subvenção à cinco professores particulares, que provem os requezitos e exigências do regulamento escolar, a juízo do referido agente.

Esse entusiasmo e a consequente liberalidade na criação de escolas começou a esmorecer ao final desse mesmo ano, premido pela carência de recursos nos cofres do município, que, como já adiantamos, não conseguira executar o recebimento da taxa escolar junto aos cidadãos locais, que insistiam na demanda por escola, mas se escusavam de pagar por ela. Requerimento para criação de escola rural e provimento na cadeira municipal da cidade, apresentado em 25 de abril, só foi analisado em 28 de julho, o que demonstra uma "desaceleração" nas frenéticas ações próinstrução do primeiro ano de funcionamento da Câmara. O parecer da comissão, apresentado nessa data, sinalizava claramente os limites:

A commissão examinando dois requerimentos assignados por diversos cidadãos desta cidade e do lugar denominado - Congonhal pedindo o provimento de cadeiras de instrucção primaria nos referidos lugares; é de parecer que sejão adiados tais provimentos ate que seja realizada a arrecadação do imposto escolar que ainda não foi recolhido no cofre, ficando o Agente executivo autorizado a provel-as logo que o fundo escolar as possa comportar. 
Com esse parecer, identificamos o ponto de inversão no movimento em prol da instrução no município e também o fator principal que impossibilitou o desenvolvimento da instrução pública brasileira nos anos iniciais da República: recursos financeiros. A responsabilidade repassada aos municípios para complementar a instrução oferecida pelo estado excedia a capacidade de suas finanças, e a incapacidade de uma arrecadação regular da taxa escolar potencializava o problema. O que fica evidente é que a motivação pela criação de um sistema de ensino existia entre a edilidade, mas não recebeu o necessário apoio, inclusive na forma de aporte financeiro, por parte do estado ou do governo federal, fazendo com que, em pouco tempo, a ampliação da oferta instrucional do município enfrentasse um gargalo, sufocando o entusiasmo e a ação iniciais.

Nova proposta de criação de escola no município só aparecerá nas atas em 24 de junho de 1895. Apesar do empenho da Câmara, nos anos seguintes, a crise financeira se agravará, ocorrendo inclusive o fechamento de diversas escolas, mas num período que excede o recorte estabelecido para o presente estudo.

\section{Considerações finais}

Nosso propósito, no presente trabalho, com a utilização da documentação consultada em duas cidades de Minas Gerais no início da República, foi aprofundar alguns pontos que temos debatido nos últimos anos referentes à presença de um esforço especial por parte dos governantes municipais em prol da instrução pública, diametralmente oposto à omissão do governo federal quando da proclamação e da implementação da República.

A responsabilidade pela instrução pública é remetida aos estados, que, por sua vez, repassam parte do encargo de criação das escolas nas sedes municipais ao poder local, obrigando-o à participação nos custos da edificação e do mobiliamento. Além disso, deixou sob a responsabilidade municipal o atendimento aos reclamos da população rural, permitindo ampla liberdade às câmaras na execução dessa responsabilidade, desde que não dependesse diretamente dos recursos do tesouro estadual.

Os municípios tentam se desincumbir dessa obrigação, mas o fazem de formas diferenciadas, tanto por sua situação política quanto eco- 
nômica. No caso de Ouro Preto, a capital do estado, por já contar com uma rede de escolas estaduais na cidade, sua posição é mais cômoda, podendo se eximir de um exame mais efetivo sobre a questão no início do funcionamento da nova Câmara, a partir de 1892. A pressão pela criação das escolas virá dos distritos, forçando a edilidade a instaurar o debate, culminando na criação de uma taxa escolar que seria cobrada nos próprios distritos para dar conta das despesas necessárias com a instrução. Nesse caso, não ocorre sequer a tentativa de atender à demanda, remetendo-se à responsabilidade distrital o encargo das escolas.

Em Uberabinha, a Câmara tenta enfrentar o problema e dar a ele encaminhamento diverso, elaborando legislação específica para a instrução, criando escolas, nomeando professores, etc., estabelecendo, inclusive, uma taxa escolar que deveria custear os gastos com a instrução pública. Esse zelo se justifica por diversos motivos, como o entusiasmo característico do início da organização do novo município; a condição anterior de distrito, que o colocara em segundo plano nas prioridades do município de Uberaba, ao qual era subordinado; à presença de uma demanda reprimida por instrução, tanto pela falta de escolas, quanto pelo estímulo à instrução gerado pela propaganda republicana; e pela crença que os vereadores demonstravam no poder regenerador e formador da educação, demonstrado em suas manifestações.

No entanto, em pouco tempo, premido pelas dificuldades financeiras, Uberabinha vê-se impossibilitado de dar continuidade a essa expansão escolar, ocorrendo estagnação e, posteriormente, suspensão e fechamento de diversas escolas.

\section{Notas}

${ }^{1}$ Para esta e as próximas citações, cf. Camara Municipal de S. Pedro de Uberabinha. Actas da Câmara. Uberabinha: 1891-1894, v. 25 (Arquivo Público Municipal de Uberlândia$M G)$.

${ }^{2}$ Para esta e as próximas citações cf. Camara Municipal de Ouro Preto. Livro de Atas da Intendência - 1890-1894. Ouro Preto: 1890-1894, Livro 0894 (Arquivo Municipal de Ouro Preto).

${ }^{3}$ Para contato com esta e as próximas três leis que serão citadas, cf. Camara Municipal de S. Pedro de Uberabinha. Leis, Decretos, Regulamentos. Uberabinha (MG): 1892, Livro 1 (Arquivo Público Municipal de Uberlândia-MG). 


\section{Referências bibliográficas}

CAMARA Municipal de Ouro Preto. Livro de Atas da Intendência - 1890-1894. Ouro Preto: 1890-1894, Livro 0894 (Arquivo Municipal de Ouro Preto).

CAMARA Municipal de S. Pedro de Uberabinha. Actas da Câmara. Uberabinha: 18911894, v. 25 (Arquivo Público Municipal de Uberlândia-MG).

CAMARA Municipal de S. Pedro de Uberabinha. Leis, Decretos, Regulamentos. Uberabinha: 1892, Livro 1 (Arquivo Público Municipal de Uberlândia-MG).

CARVALHO, José Murilo de. Os bestializados: o Rio de Janeiro e a República que não foi. São Paulo: Companhia das Letras, 1998.

GONÇALVES NETO, Wenceslau. O município e a educação em Minas Gerais: a implementação da instrução pública no início do período republicano. Anais, IV Congresso de Pesquisa e Ensino de História da Educação em Minas Gerais. Juiz de Fora: Universidade Federal de Juiz de Fora, 7 a 10 de maio de 2007.

JOSÉ, Oiliam. A propaganda republicana em Minas. Belo Horizonte: Edições da Revista Brasileira de Estudos Políticos, 1960.

MELLO, Maria Tereza Chaves de. A República consentida: cultura democrática e científica do final do Império. Rio de Janeiro: Editora FGV/EDUR, 2007.

MINAS GERAIS. Collecção das Leis e Decretos do Estado de Minas Geraes em 1891. Ouro Preto: Imprensa Official de Minas Geraes, 1892.

MINAS GERAIS. Collecção das Leis e Decretos do Estado de Minas Geraes em 1892. Ouro Preto: Imprensa Official de Minas Geraes, 1893.

MINAS GERAIS. Colleção das Leis e Decretos do Estado de Minas Geraes em 1893. Ouro Preto: Imprensa Official de Minas Geraes, 1894.

PESSOA, Reynaldo Carneiro (Org.). A idéia republicana no Brasil, através dos documentos. São Paulo: Alfa-Omega, 1973.

RESENDE, Maria Efigênia Lage de. Formação da estrutura de dominação em Minas Gerais: o novo PRM (1889-1906). Belo Horizonte: UFMG/PROED, 1982.

SILVEIRA Neto. Instituições republicanas mineiras. Belo Horizonte: Lemi; FDUFMG, 1978. VIANNA, Paulo Domingues. (Org.). Constituição Federal e Constituições dos Estados. Rio de Janeiro: editora [ilegível], 1911.

Endereço para correspondência: Universidade Federal de Uberlândia Av. João Naves de Ávila s/n Campus Santa Mônica Santa Mônica 38408-100 Uberlandia - MG

Data de recebnimento: 09/12/2008 Data de aprovação: 30/10/2009 